\title{
Expression and role of SIRT1 in hepatocellular carcinoma
}

\author{
HA NA CHOI, JUN SANG BAE, URANGOO JAMIYANDORJ, SANG JAE NOH, HO SUNG PARK, \\ KYU YUN JANG, MYOUNG JA CHUNG, MYOUNG JAE KANG, DONG GEUN LEE and WOO SUNG MOON
}

\begin{abstract}
Department of Pathology, Chonbuk National University, Medical School, Institute for Medical Sciences, Research Institute of Clinical Medicine, and Research Institute for Endocrine Sciences, Jeonju 561-756, Republic of Korea
\end{abstract}

Received March 10,2011; Accepted April 19, 2011

DOI: 10.3892/or.2011.1301

\begin{abstract}
Silent mating type information regulation 2 homolog 1 (SIRT1) is a multifaceted, nicotinamide adenine dinucleotide-dependent protein deacetylase with involvement in a wide variety of cellular processes ranging from cancer to aging. Expression of SIRT1 was evaluated in 90 cases of hepatocellular carcinoma (HCC) and five HCC cell lines. The relationship between the mutation status of p53 and expression of SIRT1 was also investigated in 10 fresh HCC tissues. Synthetic small interfering RNA was used to silence SIRT1 gene expression by RNA interference (RNAi), and cell growth and cell cycle progression were assessed. Expression of SIRT1 was significantly elevated in the HCC tissues when compared to that of non-tumor tissues $(\mathrm{p}<0.001)$. Overexpression of SIRT1 and p53 was observed in 56\% (50 of 90) and in 30\% (27 of 90) of the HCCs, respectively. Expression of SIRT1 showed significant correlation with gender $(p=0.023)$, serum AFP levels $(p=0.030)$, viral infection $(p=0.005)$ and $p 53$ expression $(\mathrm{p}<0.021)$. Western blot analysis found no correlation between p53 mutation and expression levels of SIRT1. SIRT1 silencing was found to induce cell growth arrest in HCC cells. These results suggest an association of SIRT1 expression with HCC development and that SIRT1 plays a role in cancer cell growth.
\end{abstract}

\section{Introduction}

Silent mating type information regulation 2 homolog 1 (SIRT1) is a nicotinamide adenine dinucleotide-dependent histone deacetylase $(1,2)$ that allows cell survival under genotoxic and oxidative stress (3-7). The role of SIRT1 in cell survival is achieved by deacetylation of key cell cycle molecules and apoptosis regulatory proteins, including Foxo family proteins (3), Ku70 (4), NF- $\mathrm{B}$ (5), and p53 (6,7). Up-regulation

Correspondence to: Professor Woo Sung Moon, Department of Pathology, Chonbuk National University, Medical School, Jeonju 561-756, Republic of Korea

E-mail:mws@chonbuk.ac.kr

Key words: hepatocellular carcinoma, silent mating type information regulation 2 homolog 1 of SIRT1 induces deacetylated inactivation of p53, which allows proliferation of cells in the presence of damaged DNA such that mutations accumulate, including those in p53 itself, leading to disruption of the cell cycle control and promotion of tumor progression (6-11). Recent studies have demonstrated overexpression of SIRT1 in cancer tissue, compared with normal tissue, suggesting that SIRT1 may act as a tumor promoter (9,12-16). However, expression of SIRT1 in HCC and its role have not been investigated.

Hepatocellular carcinoma (HCC) is the six th most common malignant tumor worldwide, with an incidence of 626,000 cases and 598,000 deaths annually, making it the third most common cause of cancer-related deaths throughout the world (17). Over the past few decades, considerable progress has been made in diagnosis and treatment of HCC. However, HCC is still associated with a high rate of mortality, and prognosis for this tumor is poor, even with treatment that is considered potentially curative (18). Moreover, molecular changes and mechanisms that regulate development and progression of HCC remain unclear.

In the present study, we examined i) SIRT1 expression in surgical specimens of human HCCs and its relationship with clinicopathological factors, ii) the relationship between mutation status of p53 and expression of SIRT1, and iii) the question of whether SIRT1 silencing by small interfering RNA affects cell growth and the cell cycle in HCC cells.

\section{Materials and methods}

Patients and specimens. The present study was approved by the Human Ethics Committee of Chonbuk National University Medical School. We performed a retrospective study of HCC specimens that were obtained from 90 patients who underwent surgical resection between 1998 and 2006 at the Chonbuk National University Hospital. Of the 90 patients with HCC, 77 were men and 13 were women. The mean age of the patients was 58 years (age range, 30-76). Hepatitis B virus (HBV) and hepatitis $\mathrm{C}$ virus (HCV) serologies were positive in 68 and 7 patients, respectively. Clinicopathological data were obtained from medical records at Chonbuk National University Hospital. Patient age at diagnosis, gender, T stage, microvessel invasion, intrahepatic metastasis, Edmonson histological grade, prothrombin time, level of serum albumin, presence of cirrhosis, etiology, and level of serum $\alpha$-fetoprotein (AFP) were recorded. 
HCC cell lines. Human HCC cell lines, HLE, HLF and Huh-7, were purchased from the Health Science Research Resources Bank (Osaka, Japan) and HepG2 was obtained from the American Type Culture Collection (Manassas, VA). In addition, the sarcomatoid HCC cell line, designated as SH-J1, which was established in our laboratory (19) was used. HepG2, HLE, and Huh-7 cell lines were cultured according to the recommendations of the cell banks.

Immunohistochemistry. For immunohistochemical staining, the Dako Envision system, which uses dextran polymers conjugated with horseradish peroxidase (Dako, Carpinteria, CA), was employed in order to avoid any endogenous biotin contamination. Briefly, after deparaffinization, tissue sections were treated with a microwave antigen retrieval procedure in $0.01 \mathrm{M}$ sodium citrate buffer for $10 \mathrm{~min}$. After blocking endogenous peroxidase, sections were incubated with Protein Block Serum-Free (Dako) at room temperature for $10 \mathrm{~min}$ in order to block non-specific staining; the sections were then incubated for $2 \mathrm{~h}$ at room temperature with anti-SIRT1 (Santa Cruz Biotechnology, Santa Cruz, CA) and p53 (Novocastra, Newcastle, UK) antibodies. Peroxidase activity was detected with the enzyme substrate 3-amino-9-ethyl carbazole. For the negative controls, sections were treated in the same manner, except that they were incubated with Tris-buffered saline without the primary antibody. The samples subjected to immunostaining were rated according to a score calculated by multiplying the intensity of the stain times the area of the stain. The intensity of cell staining was graded according to the following scale: 0 , no staining; $1+$, mild staining; $2+$, moderate staining; $3+$ strong staining. The area of staining was evaluated according to the following scale: $0,0-9 \%$ of cells stained positive; $1+, 10-29 \%$ of cells stained positive; $2+$, $30-69 \%$ of cells stained positive; $3+,>70 \%$ of cells stained positive. The maximum combined score was 9 , and the minimum score was zero. Since non-malignant hepatocytes can also express SIRT1, scores in tumors at least one scale more than that of the corresponding non-tumor tissues were defined as positive (SIRT1 combined score in tumor tissue vs. combined score in non-tumor tissue). Samples with nuclear p53 staining of at least $10 \%$ of the tumor cells were defined as positive.

TA-cloning and DNA sequencing for p53. The RNeasy Plus Micro kit (Qiagen, Hilden, Germany) was used according to the manufacturer's protocol for extraction of total RNA from $10 \mathrm{mg}$ of frozen tumor tissues and HCC cells. Reverse transcription was performed using avian myeloblastosis virus (AMV) reverse transcriptase (CosmoGenetech, Seoul, Korea) with an oligo (dT) primer supplied by the RT-Premix kit. The reaction product was incubated at $70^{\circ} \mathrm{C}$ for $10 \mathrm{~min}$, and iced for $5 \mathrm{~min}$ to allow the primer to anneal, at $45^{\circ} \mathrm{C}$ for $60 \mathrm{~min}$ for reverse transcription, and then at $95^{\circ} \mathrm{C}$ for $5 \mathrm{~min}$. The primer set for amplification of a human p53 cds was designed according to GenBank NM_000546, using forward primers, 5'-ATGGAGGAGCCGCAGTCAGATCCTAGCGTCGAG-3' and reverse primers, $5^{\prime}$-TCAGTCTGAGTCAGGCCCTTCTGT CTTGAA-3'. PCR conditions were $95^{\circ} \mathrm{C}$ for $45 \mathrm{sec}, 60^{\circ} \mathrm{C}$ for $45 \mathrm{sec}$, and $72^{\circ} \mathrm{C}$ for $90 \mathrm{sec}$ for 35 cycles using LaboPass pfu polymerase (CosmoGenetech). PCR products of the human p53 were purified using a LaboPass PCR purification kit
(CosmoGenetech) and cloned into a pCR2.1 vector (Invitrogen, Carlsbad, CA). We obtained 5-18 clones for each individual sample. Theoretically, it would be logical to obtain at least 10 clones for each individual sample; however, in practical terms, obtaining 10 clones from some samples was difficult. Therefore, we attempted to sequence as many clones as possible, using a BigDye Terminator Cycle Sequencing Ready Reaction Kit (Applied Biosystems, Foster City, CA) with an ABI PRISM 3730xl Genetic Analyzer (Applied Biosystems).

Western blotting. Total protein was extracted in $1 \%$ Nonidet P-40 buffer (50 mM Tris-HCl, $150 \mathrm{mM} \mathrm{NaCl}, 1 \mathrm{mM}$ EDTA) supplemented with a protease inhibitor cocktail (Sigma, St. Louis, MO) and phosphatase inhibitor cocktail I and II (Sigma), and the lysate was incubated on ice for $10 \mathrm{~min}$ and centrifuged at $13,000 \mathrm{rpm}$ for $10 \mathrm{~min}$ at $4^{\circ} \mathrm{C}$. The Coomassie blue method (Bio-Rad protein assay, Bio-Rad, Richmond, CA) was used for determination of the protein concentration. Protein samples were separated by electrophoresis on an $8 \%$ SDS-polyacrylamide gel, and the separated proteins were electrotransferred to a polyvinylidene difluoride (PVDF) membrane using a semidry transfer method (Bio-Rad). The membrane was then blocked with 5\% non-fat dry milk in Tris-buffered saline (TBS)-0.1\% Tween-20 (15 mM NaCl, $100 \mathrm{mM}$ Tris- $\mathrm{HCl}, \mathrm{pH}$ 7.5) for $1 \mathrm{~h}$ in order to reduce non-specific binding. The membrane was incubated with antiSIRT1 (Santa Cruz Biotechnology, Santa Cruz, CA), anti-p53 (Novocastra) and anti-acetylated p53 (Santa Cruz Biotechnology) overnight at $4^{\circ} \mathrm{C}$. After washing 3 times with TBST, the membrane was incubated for $1 \mathrm{~h}$ at room temperature with the corresponding secondary antibodies, and immune complexes were visualized using an ECL detection system (Amersham Biosciences, Buckinghamshire, UK); they were then exposed to a luminescent image analyzer (LAS-3000, Fuji Film, Tokyo, Japan). Equal loading of proteins in each lane was confirmed by probing of the membrane with mouse anti- $\beta$-actin (Sigma).

Small interfering RNA transfection. Small interfering RNA (siRNA) sequences were used for silencing of SIRT1 expression. SIRT1 siRNA and negative control were purchased from Bioneer Corporation (Daejeon, Korea). Sequences for SIRT1-specific siRNAs and negative control siRNA were as follows: SIRT1, sense 5'-CUGUGAAAUUACUGCAAGA(dT dT)-3'; antisense 5'-UCUUGCAGUAAUUUCACAG(dTdT)-3' and negative control, sense 5'-CCUACGCCACCAAUUUCG U(dTdT)-3'; antisense 5'-ACGAAAUUGGUGGCGUAGG (dTdT)-3'.

Transfection of siRNA was performed with Lipofectamine RNAiMAX transfection reagent (Invitrogen) following the manufacturer's protocol. Briefly, one day prior to transfection, cells were seeded in a 6-well plate with antibiotic-free serum. At the time of transfection, cell confluence was $50 \%$ and the medium was replaced with antibiotic-free growth medium. SIRT1 and negative control siRNA were diluted in $500 \mu 1$ of DMEM, followed by addition of $5 \mu$ l Lipofectamine RNAi MAX reagent; it was then left to stand at room temperature for $20 \mathrm{~min}$. The diluted RNAi-Lipofectamine RNAiMAX mixture was added to the cells. The cells were incubated at $37^{\circ} \mathrm{C}$ in a $\mathrm{CO}_{2}$ incubator for $48 \mathrm{~h}$. After $48 \mathrm{~h}$, the cells were 


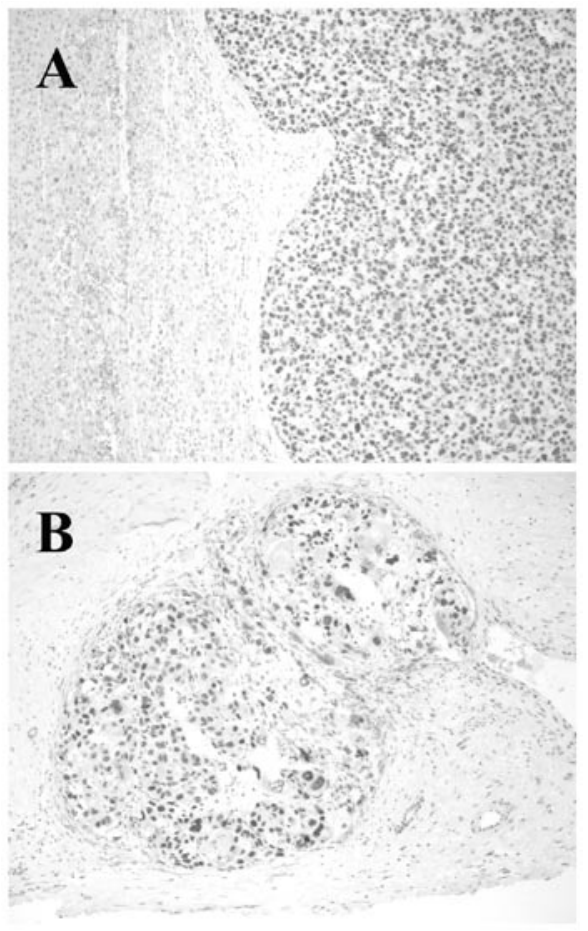

Figure 1. Immunohistochemical staining for SIRT1 in hepatocellular carcinoma. (A) Well-differentiated HCC. (B) Poorly differentiated HCC

harvested, and expression of the transfected gene was evaluated by Western blotting.

Cell growth and proliferation assay. Cell growth was determined by the colorimetric tetrazolium derived XTT (sodium 3'-[1-(phenylaminocarbonyl)-3,4-tetrazolium]-bis (4-methoxy6-nitro) benzene sulfonic acid hydrate) assay (Roche Applied Science, Mannheim, Germany), and DNA synthesis of cells was assessed by the BrdU (bromodeoxyuridine) incorporation assay (Roche Applied Science). For the cell growth and proliferation assay, at $48 \mathrm{~h}$ after transfection of siRNA, the cells of each group were re-seeded in 96-well plates at a density of $0.3-1 \times 10^{4}$ cells per well. After $24-48 \mathrm{~h}$, XTT and incorporated BrdU were measured colorimetrically using a microtiter plate reader (Bio-Rad) at a wavelength of $450 \mathrm{~nm}$.

Cell cycle analysis. Cells in 6-well plates were transfected with SIRT1 siRNA using the Lipofectamine RNAiMAX reagent. Forty-eight hours after transfection, cells were washed with PBS and fixed in $70 \%$ ethanol. Cells were treated with RNase at $37^{\circ} \mathrm{C}$ for $30 \mathrm{~min}$, and then incubated with propidium iodide $(10 \mu \mathrm{g} / \mathrm{ml})$. Percentages of cells in different phases of the cell cycle were measured with a FACStar flow cytometer (Becton-Dickinson, San Jose, CA) and analyzed using Lysis II and CellFIT software (Becton-Dickinson) or ModFit software (Verity Software House, Inc., Topsham, ME).

Statistical analysis. Comparisons between SIRT1 expression and clinical factors were tested by the $\chi^{2}$ test. Differences in the SIRT1 expression score between HCC and non-malignant hepatocytes were tested by the Mann-Whitney rank sum test. P-values $<0.05$ were considered to indicate statistical significance.

\section{Results}

Immunohistochemical staining of SIRT1 and p53 in HCC. SIRT1 expression in HCC was significantly up-regulated $(2.70 \pm 0.3)$ compared to that in the non-malignant hepatocytes $(0.19 \pm 0.1)(\mathrm{p}<0.001)$. Overexpression of SIRT1 was observed in 50 out of $90(56 \%)$ HCC specimens, when compared with the non-malignant hepatocytes. In HCC cells, SIRT1 expression was predominantly localized to the nucleus; however, in some cells, it was localized to both the nucleus and cytoplasm (Fig. 1). Overexpression of p53 was observed in 27 of 90 (30\%) of the HCC tissues. Our statistical results showed a significant association between expression of SIRT1 and expression of p53 (p<0.05) (Table I).

Association of SIRT1 expression with clinicopathological factors of hepatocellular carcinoma patients. For the $90 \mathrm{HCC}$ patients, significant associations were observed between SIRT1 expression and gender, serum AFP level, etiology (viral vs. non-viral) and $\mathrm{p} 53$ expression $(\mathrm{p}=0.023, \mathrm{p}=0.03, \mathrm{p}=0.005$, $\mathrm{p}=0.021$, respectively). Clinicopathological features of HCC patients and their relationships between SIRT1 expression are shown in Table I.

p53 mutation and SIRT1 expression. A mutation in the p53 gene often results in a prolonged half-life of the protein, compared to the wild-type and loss of function (20). The mutated p53 protein tends to accumulate in cell nuclei and can be analyzed immunohistochemically. Therefore, positive nuclear staining suggests mutated or overexpressed p53. Immunohistochemical study revealed a significant association between SIRT1 expression and expression of p53; therefore, the relationship between SIRT1 expression and p53 mutation in the HCC cell lines and HCC tissues was examined.

Of the 10 HCC tissues, five tissues showed the mutant p53 gene. The majority of mutations were single nucleotide substitutions (point mutations). One HCC tissue showed 2 types of mutations: the insertion mutation and the missense mutation. The mutation of p53 was found to occur primarily in the exon 5 [a hot spot (exon 5-8)] region (Table II). The p53 gene mutation was also identified in the HCC cell lines. p53 gene mutation analysis of HepG2 and SH-J1 cells indicated the wild-type form. In contrast, Huh-7 cells had 1 missense mutation in exon 6 while HLF and HLE cells had 1 missense mutation in exon 7 (Table III). Using Western blotting, we evaluated expression of SIRT1 and p53 in five different human HCC cell lines (p53 wild-type cell lines, HepG-2, SH-J1; and p53-mutated type cell lines, Huh-7, HLF, and HLE). The expression level of the $\mathrm{p} 53$ protein was higher in the $\mathrm{p} 53$-mutated type HCC cell lines than in the p53 wild-type HCC cell lines. No difference was observed in the expression level of SIRT1 between the p53 wild-type HCC cell lines and the p53-mutated HCC cell lines (Fig. 2A). Similar to the results for the HCC cell lines, no correlation was observed between p53 mutation and the SIRT1 expression level in the HCC tissues (Fig. 2B).

Silencing of SIRT1 acetylated 553 protein. Since SIRT1 is known to deacetylate p53 protein, expression levels of acetylated p53 and SIRT1 were evaluated in SIRT1 siRNAtransfected HepG2 (p53 wild-type) and HLF (p53-mutated 
Table I. Clinicopathological characteristics of the HCC patients and correlation with SIRT1 expression.

\begin{tabular}{|c|c|c|c|c|c|c|c|c|c|c|}
\hline \multirow{2}{*}{ Characteristics } & \multirow{2}{*}{$\begin{array}{l}\text { No. of } \\
\text { cases }\end{array}$} & \multicolumn{3}{|c|}{ SIRT1 expression } & \multirow{2}{*}{$\begin{array}{l}\text { Case } \\
\text { no. }\end{array}$} & \multirow{2}{*}{$\begin{array}{c}\text { Age } \\
\text { (years) }\end{array}$} & \multirow{2}{*}{ Gender } & \multirow{2}{*}{$\begin{array}{l}\text { Nucleotide } \\
\text { change }\end{array}$} & \multirow{2}{*}{ Region } & \multirow{2}{*}{$\begin{array}{l}\text { Predicted } \\
\text { effect }\end{array}$} \\
\hline & & Negative & Positive & P-value & & & & & & \\
\hline & & & & & 1 & 66 & Female & - & - & - \\
\hline Age (years) & & & & & 2 & 66 & Male & - & - & - \\
\hline$<60$ & 48 & 19 & 29 & 0.321 & 3 & 67 & Male & - & - & - \\
\hline$\geq 60$ & 42 & 21 & 21 & & 4 & 63 & Female & - & - & - \\
\hline Gender & & & & & 5 & 72 & Male & - & - & - \\
\hline Female & 13 & 2 & 11 & 0.023 & 6 & 49 & Male & c. $524 \mathrm{G}>\mathrm{T}$ & Exon 5 & p.R175L \\
\hline Male & 77 & 38 & 39 & & 7 & 69 & Male & c. $536 \mathrm{~A}>\mathrm{G}$ & Exon 5 & p.H179R \\
\hline T stage & & & & & 8 & 54 & Male & c. $501 \mathrm{G}>\mathrm{T}$ & Exon 5 & p.Q167H \\
\hline $\mathrm{T} 1$ & 38 & 13 & 25 & 0.372 & 9 & 46 & Male & c. $359 \_360$ ins.6 & Exon 4 & Insertion \\
\hline $\mathrm{T} 2$ & 27 & 13 & 14 & & & & & c. $542 \mathrm{~A}>\mathrm{G}$ & Exon 5 & p.H181R \\
\hline $\mathrm{T} 3$ & 14 & 8 & 6 & & 10 & 55 & Male & c. $1010 \mathrm{G}>\mathrm{T}$ & Exon 11 & p.R337L \\
\hline $\mathrm{T} 4$ & 11 & 6 & 5 & & & & & & & \\
\hline
\end{tabular}

Microvessel invasion

Absent

Present

$44 \quad 16 \quad 28$

46

24

22

Intrahepatic metastasis

Absent

59

Present

24

35

0.321

Histological grade

Low

High

Ascites

Absent

Present

PT-INR

Normal

Prolonged

16

15

Albumin

$\geq 3.5 \mathrm{~g} / \mathrm{dl}$

$<3.5 \mathrm{~g} / \mathrm{dl}$

68

31

37

13

0.701

22

9

50

0.110

2

38

2

AFP

$<400 \mathrm{ng} / \mathrm{ml}$

$\geq 400 \mathrm{ng} / \mathrm{ml}$

Liver cirrhosis

Absent

Present

79

11

36

43

7

0.565

4

43

0.565

11

36

7

69

35

34

0.030

21

5

16

p53 expression

Negative

Positive

35

20

15

0.053

55

35

Etiology

Viral

Non-viral
63

27

76

14
Table II. p53 gene mutations in the hepatocellular carcinoma tissues.

Table III. p53 gene mutations in the hepatocellular carcinoma cell lines.

Cell name Nucleotide change Region Predicted effect

\begin{tabular}{lccc}
\hline HepG2 & - & - & - \\
SH-J1 & - & - & - \\
Huh-7 & c.659A $>$ G & Exon 6 & p.Y220C \\
HLF & c.731G $>$ C & Exon 7 & p.G244A \\
HLE & c.731G $>$ C & Exon 7 & p.G244A
\end{tabular}

Down-regulation of SIRT1 in the HepG2 and HLF cells resulted in accumulation of acetylated p53 by 39 and $88 \%$ when compared to that of the control, respectively (Fig. 3).

Effects of SIRT1 silencing on cell growth and cell proliferation. SIRT1 silencing of HepG2 and HLF cells resulted in a significant inhibition of cell growth when compared to that of the control ( $\mathrm{p}<0.001)$ (Fig. 4A). Down-regulation of SIRT1 in HepG2 and HLF cells by SIRT1 siRNA resulted in decreased cell proliferation when compared to that of the control, but without statistical significance (Fig. 4B).

Silencing of SIRT1 induces G1 arrest in HepG2 cells. The effect of SIRT1 siRNA transfection on cell cycle distribution was determined in HepG2 and HLF cells by flow cytometry. Down-regulation of SIRT1 in the HepG2 cells induced an increase in $\mathrm{G} 1$ phase arrest up to $55 \%(\mathrm{p}<0.001)$ (Fig. 5A). However, specific phase arrest was not observed in the SIRT1down-regulated HLF cells (Fig. 5B).

\section{Discussion} protein.

type) cell lines. Transfection with SIRT1 siRNA resulted in decreased SIRT1 protein expression by 75 and $81 \%$ at $48 \mathrm{~h}$ post-transfection in the HepG2 and HLF cells, respectively.
SIRT1 has been regarded as a tumor promoter due to its increased expression in some types of cancers and its role in the inactivation of proteins involved in tumor suppression and DNA damage repair $(8-10,12,15)$. However, in a recent study, 
A

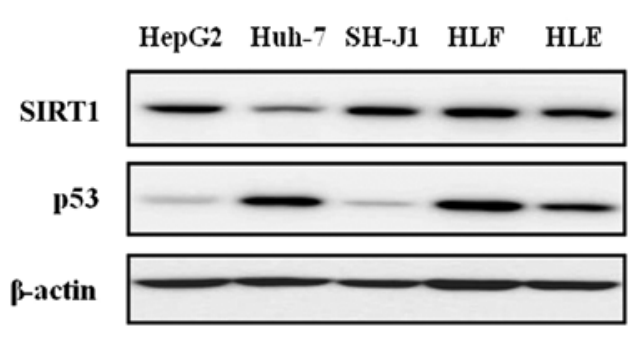

B

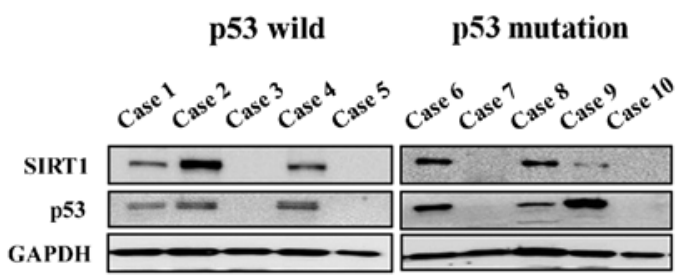

Figure 2. (A) Western blot analysis of SIRT1 and p53 in hepatocellular carcinoma cell lines. No difference in SIRT1 expression levels was observed between p53 wild-type (HepG2, SH-J1) and p53-mutated type (Huh-7, HLF, HLE) cell lines. (B) Expression of SIRT1 and p53 in the HCC tissues. A correlation was noted between SIRT1 expression and p53 expression. However, no difference in SIRT1 expression levels was observed between p53 wild-type and p53-mutated HCC.

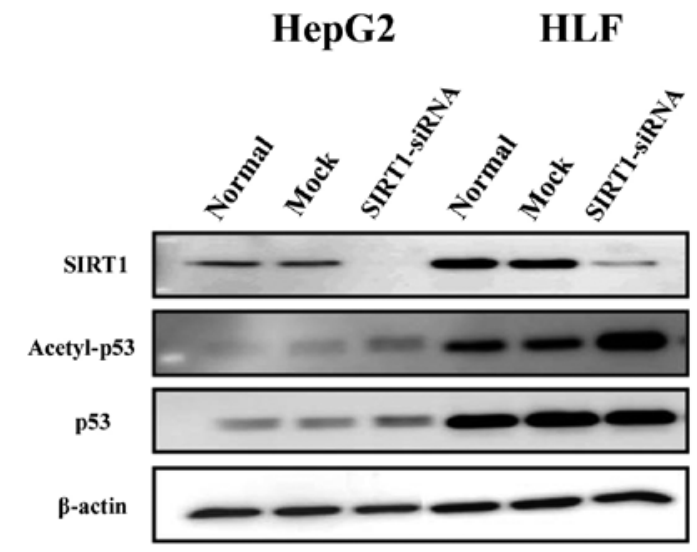

Figure 3. Western blot analysis of SIRT1, acetyl-p53, and p53 in hepatocellular carcinoma cell lines. Each HepG2 and HLF cell line transfected with SIRT1 siRNA presented a decreased expression level of SIRT1 and an increased expression level of acetylated 553 .

reduced SIRT1 levels were demonstrated in other types of cancers, and SIRT1 deficiency was shown to result in genetic instability and tumorigenesis (21). Whether SIRT1 acts as a tumor promoter or tumor suppressor remains controversial. The present study demonstrated that i) expression of SIRT1 was significantly elevated in HCC tissues when compared to non-tumor tissues; ii) expression of SIRT1 showed significant correlation with p53 expression in HCC tissues by immunohistochemistry; iii) Western blot analysis found no correlation between p53 mutation and the SIRT1 expression level; iv) expression of SIRT1 was associated with gender, serum AFP level, and viral infection in HCC patients; and v) SIRT1 silencing induced significant inhibition in the viability and growth of human HCC cells.
A

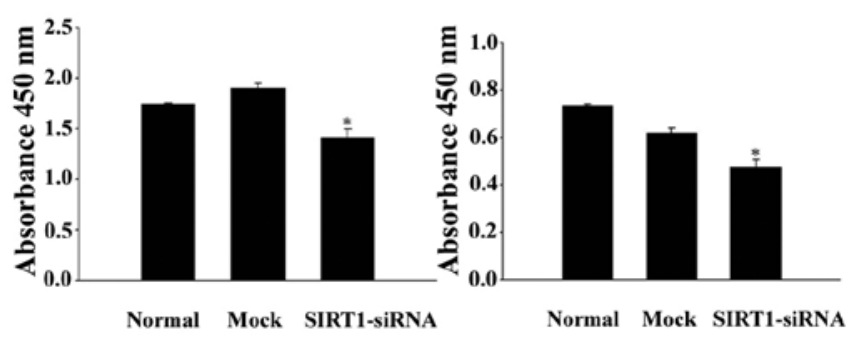

B

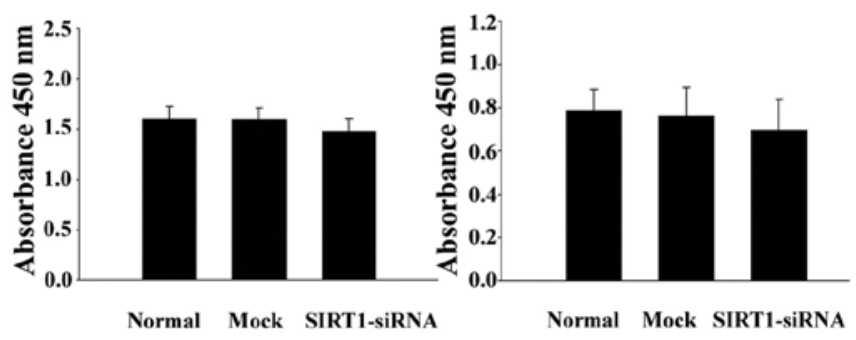

Figure 4. XTT and BrdU proliferation assays for SIRT1 in hepatocellular carcinoma cell lines. As indicated by the XTT assay, down-regulation of SIRT1 (A, left) and HLF cells (right) resulted in a significantly decreased cell growth in the HepG2 cells when compared to that of the control, respectively $(\mathrm{p}<0.001)$. In the $\mathrm{BrdU}$ assay, SIRT1 down-regulation in HepG2 cells $(B$, left) and HLF cells (right) resulted in decreased cell proliferation when compared to that of the control, but without statistical significance.

Down-regulation of normal SIRT1 protein observed during ageing is lost in cancer cells, rendering them resistant to replicative senescence after oxidative stress and facilitating tumor development due to less induction of apoptosis by $\mathrm{p} 53$ in response to DNA damage (6-11). In our study, significantly elevated expression of SIRT1 was observed in HCC tissues when compared to non-tumor tissues. Increased expression of SIRT1 has been reported in various types of malignant tumors, including human cutaneous tumors (12), and breast (13), colon (13), prostate (14), and mouse cancers (9). In addition, SIRT1 expression has been suggested as a possible prognostic indicator in human malignant lymphoma (16) and gastric cancer (22). Thus, our present results and previous data suggest that SIRT1 expression may act as a tumor promoter and may increase the risk of cancer. However, this issue remains controversial. In contrast to our results, a previous study demonstrated the down-regulation of SIRT1 in colon tumors (23) and its antitumor properties (24). Despite frequent overexpression of SIRT1 in malignant ovarian serous tumors, increased expression of SIRT1 showed a correlation with increased overall survival (15). In addition, a recent study demonstrated suppressed intestinal tumor formation due to enhanced SIRT1 expression in a $\beta$-catenindependent mouse model of colon cancer, thereby indicating that the effects of SIRT1 may vary in different tumor models, depending on downstream targets of the enzyme (25). Further analysis of SIRT1 expression by cancer cells is required for determination of its mechanism of action and its importance in carcinogenesis. 
$\mathbf{A}$
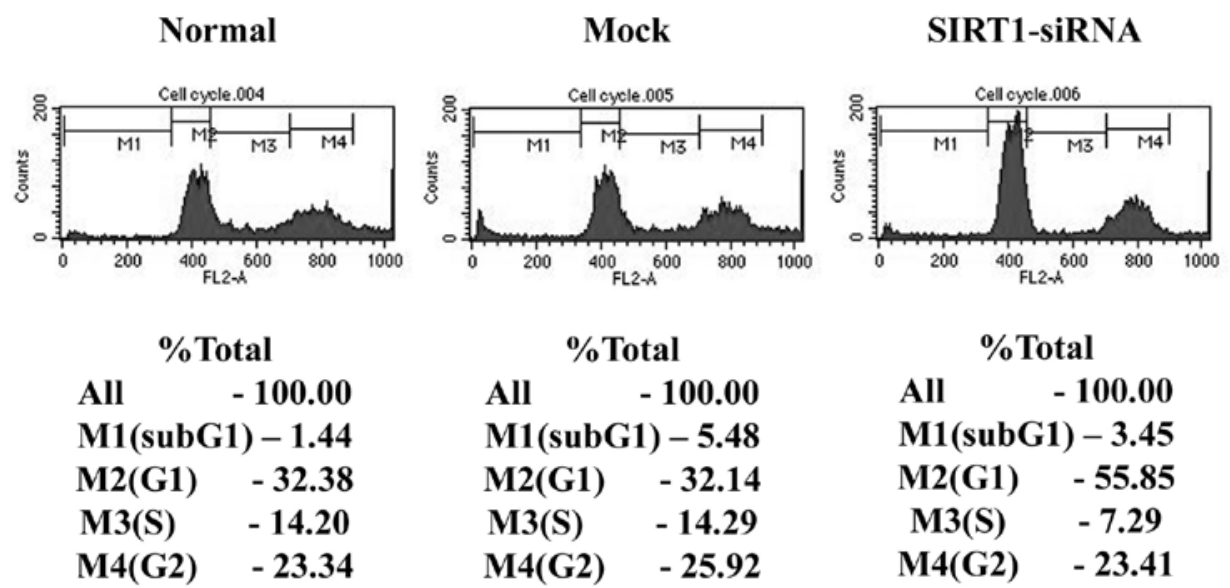

B
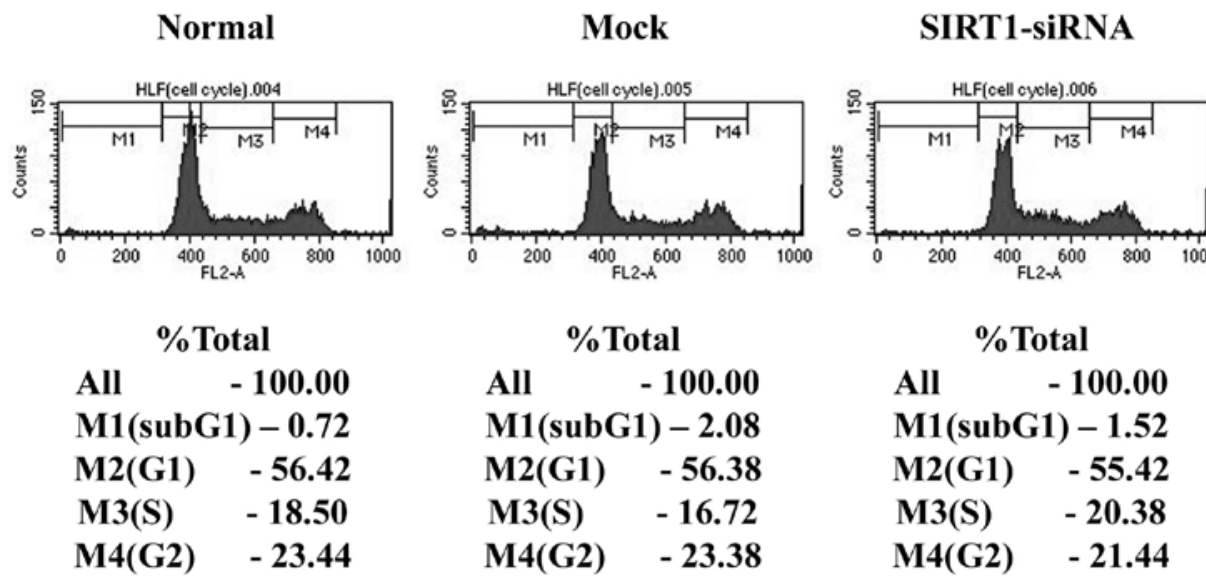

Figure 5. Cell cycle analysis in hepatocellular carcinoma (A) HepG2 and (B) HLF cell lines. HepG2 cells transfected with SIRT1 siRNA showed 55\% G1 arrest.

Reciprocal regulation occurs between SIRT1 and p53. SIRT1 binds and deacetylates activated p53 $(6,7)$, while activated p53 induces down-regulation of SIRT1 translation via miR-34a (26). Therefore, the possible correlation between SIRT1 and p53 expression status was investigated in HCC tissues. In the present study, expression of SIRT1 showed a significant correlation with p53 expression in HCC tissues, suggesting a close association of SIRT1 expression with p53. The mutated p53 protein tended to accumulate in cell nuclei, and positive nuclear staining in the immunohistochemistry indicated mutated $\mathrm{p} 53$. These findings suggest a possible role of mutated p53 in the increased expression of SIRT1 by inducing disturbance of the repressed function of p53 in the expression of SIRT1. The relationship between SIRT1 expression and p53 mutation was examined in HCC cell lines and HCC tissues. Although p53 mutation might be expected to affect SIRT1 expression, this study did not demonstrate a significant association between p53 mutation and the SIRT1 expression level in the Western blot analysis.

In the present study, a significant association was found between SIRT1 expression and HBV infection in HCC patients. HBV infection can promote carcinogenesis by at least 3 different mechanisms (27-29). First, insertional mutations of HBV are known to activate endogenous genes with involvement in cell cycle control, cellular proliferation, and differentiation. Second, integration of viral DNA into the host genome can induce chromosomal instability. The third mechanism of carcinogenesis linked to HBV infection is based on expression of viral proteins, particularly HBx, in the modulation of cell proliferation and viability. Binding of HBV DNA to p53 protein, resulting in inactivation of p53 transactivation, has already been established (28). Alteration of several new genes by HBV integration in tumors has recently been reported, suggesting that viral integration in the vicinity of genes controlling cell proliferation, viability, and differentiation is a mechanism with frequent involvement in $\mathrm{HBV}$ hepatocarcinogenesis $(29,30)$. Allison et al (31) demonstrated that exogenous expression of human papilloma virus (HPV) E7 in primary human keratinocytes induces abnormally high levels of SIRT1 protein. HPV E7 is also required for maintenance of abnormally high levels of SIRT1 protein expression in cervical cancer cells. In addition, the ability of HPV E7 to up-regulate SIRT1 appears to be linked with HPV E7-mediated suppression of apoptosis in cervical cancer cells $(31,32)$. Our observations, together with those of previous studies, suggest a possible interaction between HBV and SIRT1, which resulted in increased expression of SIRT1 protein and prolonged tumor cell survival.

Our study found a significant association of elevated serum AFP with SIRT1 overexpression in HCC patients. The AFP gene is regulated primarily by the positive transcriptional regulatory factor hepatocyte nuclear factor 1 (HNF1) and a 
negative transcriptional factor, AT-motif-binding factor 1 (ATBF1) (33). p53 is also involved in the negative regulation of AFP gene expression through alteration of chromatin structure at the core promoter $(34,35)$. Little is known regarding the relationship between expression or the role of SIRT1 and AFP production in HCC. Only one previous study has demonstrated strong repression of AFP promoter activity by $\mathrm{p} 53$, while SIRT1 binds and deacetylates the $\mathrm{p} 53$ protein, reducing its transcriptional activity, resulting in increased AFP promoter activity in HepG2 cells (36).

Our study revealed that SIRT1 silencing leads to an increase in acetylated p53 and induces cell growth arrest in $\mathrm{HCC}$ cells. Our findings are in agreement with those of previous studies demonstrating that SIRT1 silencing by RNA interference induces growth arrest and/or apoptosis in human colorectal carcinoma cells (37). SIRT1 inhibitor, sirtinol, induced senescence-like growth arrest characterized by induction of senescence-associated $\beta$-galactosidase activity in human breast cancer MCF-7 cells and lung cancer H1299 cells (38). In addition, a recent study demonstrated that SIRT1 inhibition via nicotinamide and sirtinol, as well as short hairpin RNA (shRNA)-mediated RNA interference, result in significant inhibition of the growth and viability of human prostate cancer cells (39). Therefore, our findings, together with those of previous studies, suggest that up-regulation of SIRT1 expression may play an important role in promotion of cell growth in HCC tissues.

In the present study, silencing of SIRT1 in p53 wild-type HepG2 cells induced G1 phase arrest, while specific phase arrest was not observed in SIRT1-down-regulated p53-mutated HLF cells. A previous study demonstrated that SIRT1 inhibition imparts an anti-proliferative response in human prostate cancer cells, irrespective of their p53 status (39). In wild-type p53 prostate cancer cells, shRNA-mediated knock-down of SIRT1 resulted in an increase in senescence, whereas, in prostate cancer cells lacking p53, SIRT1 knockdown resulted in induction of apoptosis (40). In contrast, Yamakuchi et al reported that inhibition of SIRT1 expression with miR-34a resulted in an increase in acetylated p53, and, ultimately, an increase in apoptosis in colon cancer cells with wild-type p53, but not in colon cancer cells lacking p53 (26). The precise mechanism of the differential anti-proliferative responses of SIRT1 inhibition in human cancer cells according to p53 status remains unclear; however, the differential effects of SITR1 on cancer cell growth may be a result of the type and location of p53 mutation as well as a potentially different gain or loss of function caused by p53 mutation. However, further in-depth studies are needed in order to dissect the molecular mechanism(s) of the observed differential response of SIRT1 inhibition in cancer cells, particularly in connection with p53.

In conclusion, SIRT1 may play a role as a tumor promoter and may also play an important role in cancer cell growth in HCC. Our findings may provide a rationale for SIRT1 inhibition as a novel therapeutic approach to suppression of proliferation of HCC cells.

\section{Acknowledgements}

This study was supported by a Grant of the National Research Foundation of Korea funded by the Korean Government (no.
2010-0029464). Paraffin tissue samples were provided by the Chonbuk National University Hospital, a member of the National Biobank of Korea, which is supported by the Ministry of Health, Welfare and Family Affairs.

\section{References}

1. Imai S, Armstrong CM, Kaeberlein M and Guarente L: Transcriptional silencing and longevity protein Sir2 is an NAD-dependent histone deacetylase. Nature 403: 795-800, 2000.

2. Voelter-Mahlknecht S and Mahlknecht U: Cloning, chromosomal characterization and mapping of the NAD-dependent histone deacetylase gene sirtuin 1. Int J Mol Med 17: 59-67, 2006.

3. Brunet A, Sweeney LB, Sturgill JF, Chua KF, Greer PL, Lin Y, Tran H, Ross SE, Mostoslavsky R, Cohen HY, Hu LS, Cheng HL, Jedrychowski MP, Gygi SP, Sinclair DA, Alt FW and Greenberg ME: Stress-dependent regulation of FOXO transcription factors by the SIRT1 deacetylase. Science 303: 2011-2015, 2004.

4. Cohen HY, Lavu S, Bitterman KJ, Hekking B, Imahiyerobo TA, Miller C, Frye R, Ploegh H, Kessler BM and Sinclair DA: Acetylation of the $\mathrm{C}$ terminus of $\mathrm{Ku} 70$ by $\mathrm{CBP}$ and PCAF controls Bax-mediated apoptosis. Mol Cell 13: 627-638, 2004.

5. Lee JH, Song MY, Song EK, Kim EK, Moon WS, Han MK, Park JW, Kwon KB and Park BH: Overexpression of SIRT1 protects pancreatic beta-cells against cytokine toxicity by suppressing the nuclear factor-kappaB signaling pathway. Diabetes 58: 344-351, 2009.

6. Luo J, Nikolaev AY, Imai S, Chen D, Su F, Shiloh A, Guarente L and $\mathrm{Gu}$ W: Negative control of p53 by Sir2 alpha promotes cell survival under stress. Cell 107: 137-148, 2001.

7. Vaziri H, Dessain SK, Ng Eaton E, Imai SI, Frye RA, Pandita TK, Guarente L and Weinberg RA: hSIR2(SIRT1) functions as an NAD-dependent p53 deacetylase. Cell 107: 149-159, 2001.

8. Baylin SB and Ohm JE: Epigenetic gene silencing in cancer, a mechanism for early oncogenic pathway addiction? Nat Rev Cancer 6: 107-116, 2006.

9. Chen WY, Wang DH, Yen RC, Luo J, Gu W and Baylin SB: Tumor suppressor HIC1 directly regulates SIRT1 to modulate p53-dependent DNA-damage responses. Cell 123: 437-448, 2005.

10. Lim CS: Human SIRT1: a potential biomarker for tumorigenesis? Cell Biol Int 31: 636-637, 2007.

11. Saunders LR and Verdin E: Sirtuins: critical regulators at the crossroads between cancer and aging. Oncogene 26: 5489-5504, 2007.

12. Hida Y, Kubo Y, Murao K and Arase S: Strong expression of a longevity-related protein, SIRT1, in Bowen's disease. Arch Dermatol Res 299: 103-106, 2007.

13. Kuzmichev A, Margueron R, Vaquero A, Preissner TS, Scher M, Kirmizis A, Ouyang X, Brockdorff N, Abate-Shen C, Farnham P and Reinberg D: Composition and histone substrates of polycomb repressive group complexes change during cellular differentiation. Proc Natl Acad Sci USA 102: 1859-1864, 2005.

14. Huffman DM, Grizzle WE, Bamman MM, Kim JS, Eltoum IA, Elgavish A and Nagy TR: SIRT1 is significantly elevated in mouse and human prostate cancer. Cancer Res 67: 6612-6618, 2007.

15. Jang KY, Kim KS, Hwang SH, Kwon KS, Kim KR, Park HS, Park BH, Chung MJ, Kang MJ, Lee DG and Moon WS: Expression and prognostic significance of SIRT1 in ovarian epithelial tumours. Pathology 41: 366-371, 2009.

16. Jang KY, Hwang SH, Kwon KS, Kim KR, Choi HN, Lee NR, Kwak JY, Park BH, Park HS, Chung MJ, Kang MJ, Lee DG, Kim HS, Shim H and Moon WS: SIRT1 expression is associated with poor prognosis of diffuse large B-cell lymphoma. Am J Surg Pathol 32: 1523-1531, 2008.

17. Parkin DM, Bray F, Ferlay J and Pisani P: Global cancer statistics, 2002. CA Cancer J Clin 55: 74-108, 2005.

18. Befeler AS and Di Bisceglie AM: Hepatocellular carcinoma: diagnosis and treatment. Gastroenterology 122: 1609-1619, 2002.

19. Kim DG, Park SY, Kim H, Chun YH, Moon WS and Park SH: A comprehensive karyotypic analysis on a newly established sarcomatoid hepatocellular carcinoma cell line SH-J1 by comparative genomic hybridization and chromosome painting. Cancer Genet Cytogenet 132: 120-124, 2002. 
20. Zambetti GP and Levine AJ: A comparison of the biological activities of wild type and mutant p53. FASEB J 7: 855-865, 1993.

21. Wang RH, Sengupta K, Li C, Kim HS, Cao L, Xiao C, Kim S, Xu X, Zheng Y, Chilton B, Jia R, Zheng ZM, Appella E, Wang XW, Ried T and Deng CX: Impaired DNA damage response, genomic instability, and tumorigenesis in SIRT1 mutant mice. Cancer Cell 14: 312-323, 2008.

22. Cha EJ, Noh SJ, Kwon KS, Kim CY, Park BH, Park HS, Lee H, Chung MJ, Kang MJ, Lee DG, Moon WS and Jang KY: Expression of DBC1 and SIRT1 is associated with poor prognosis of gastric carcinoma. Clin Cancer Res 15: 4453-4459, 2009.

23. Ozdag H, Teschendorff AE, Ahmed AA, Hyland SJ, Blenkiron C, Bobrow L, Veerakumarasivam A, Burtt G, Subkhankulova T, Arends MJ, Collins VP, Bowtell D, Kouzarides T, Brenton JD and Caldas C: Differentiatial expression of selected histone modifier genes in human solid cancers. BMC Genomics 7: 90, 2006.

24. Yeung F, Hoberg JE, Ramsey CS, Keller MD, Jones DR, Frye RA and Mayo MW: Modulation of NF-kappaB-dependent transcription and cell survival by the SIRT1 deacetylase. EMBO J 23: 2369-2380, 2004.

25. Firestein R, Blander G, Michan S, Oberdoerffer P, Ogino S, Campbell J, Bhimavarapu A, Luikenhuis S, de Cabo R, Fuchs C, Hahn WC, Guarente LP and Sinclair DA: The SIRT1 deacetylase suppresses intestinal tumorigenesis and colon cancer growth. PLoS One 3: e2020, 2008.

26. Yamakuchi $M$, Ferlito $M$ and Lowenstein CJ: miR-3a repression of SIRT1 regulates apoptosis. Proc Natl Acad Sci USA 105: 13421-13426, 2008.

27. Lupberger J and Hildt E: Hepatitis B virus-induced oncogenesis. World J Gastroenterol 13: 74-81, 2007.

28. Qu J, Lin J, Zhang S, Zhu Z, Ni C, Zhang S, Gao H and Zhu M HBV DNA can bind to P53 protein and influence p53 transactivation in hepatoma cells. Biochem Biophys Res Commun 386: 504-509, 2009.

29. Oyagbemi AA, Azeez OI and Saba AB: Hepatocellular carcinoma and the underlying mechanisms. Afr Health Sci 10: 93-98, 2010

30. Murakami Y, Saigo K, Takashima H, Minami M, Okanoue T, Bréchot $\mathrm{C}$ and Paterlini-Bréchot $\mathrm{P}$ : Large-scaled analysis of hepatitis B virus (HBV) DNA integration in HBV-related hepatocellular carcinomas. Gut 54: 1162-1168, 2005.
31. Allison SJ, Jiang M and Milner J: Oncogenic viral protein HPV E7 up-regulates the SIRT1 longevity protein in human cervical cancer cells. Aging 1: 316-327, 2009.

32. Jiang $M$ and Milner J: Selective silencing of viral gene expression in HPV-positive human cervical carcinoma cells treated with siRNA, a primer of RNA interference. Oncogene 21: 6041-6048, 2002.

33. Ninomiya T, Mihara K, Fushimi K, Hayashi Y, HashimotoTamaoki $\mathrm{T}$ and Tamaoki T: Regulation of the alpha-fetoprotein gene by the isoforms of ATBF1 transcription factor in human hepatoma. Hepatology 35: 82-87, 2002.

34. Lee KC, Crowe AJ and Barton MC: p53-mediated repression of alpha-fetoprotein gene expression by specific DNA binding. Mol Cell Biol 19: 1279-1288, 1999.

35. Ogden SK, Lee KC, Wernke-Dollries K, Stratton SA, Aronow B and Barton MC: p53 targets chromatin structure alteration to repress alpha-fetoprotein gene expression. J Biol Chem 276: 42057-42062, 2001.

36. Kataoka H, Bonnefin P, Vieyra D, Feng X, Hara Y, Miura Y, Joh T, Nakabayashi H, Vaziri H, Harris CC and Riabowol K: ING1 represses transcription by direct DNA binding and through effects on p53. Cancer Res 63: 5785-5792, 2003.

37. Ford J, Jiang $M$ and Milner J: Cancer-specific functions of SIRT1 enable human epithelial cancer cell growth and survival. Cancer Res 65: 10457-10463, 2005.

38. Ota H, Tokunaga E, Chang K, Hikasa M, Iijima K, Eto M, Kozaki K, Akishita M, Ouchi Y and Kaneki M: Sirtl inhibitor, Sirtinol, induces senescence-like growth arrest with attenuated Ras-MAPK signaling in human cancer cells. Oncogene 25: 176-185, 2006.

39. Jung-Hynes B, Nihal M, Zhong W and Ahmad N: Role of sirtuin histone deacetylase SIRT1 in prostate cancer. A target for prostate cancer management via its inhibition? J Biol Chem 284: 3823-3832, 2009

40. Jung-Hynes B and Ahmad N: Role of p53 in the anti-proliferative effects of Sirtl inhibition in prostate cancer cells. Cell Cycle 8: 1478-1483, 2009. 